\title{
SIMULATIONS OF HOT-GAS FLOW IN INTERNALLY COOLED CASCADE OF TURBINE VANES
}

\author{
Janusz Sznajder \\ Łukasiewicz Research Network - Institute of Aviation, Department of Aerodynamics \\ Krakowska Av. 110/114, 02-256 Warsaw, Poland \\ tel.: +48228460011 ext. 492, fax: +48228464432 \\ e-mail: janusz.sznajder@ilot.edu.pl
}

\begin{abstract}
An experiment in cooling of gas turbine nozzle guide vanes was modelled numerically with a conjugate viscousflow and solid-material heat conduction solver. The nozzle vanes were arranged in a cascade and operated in highpressure, hot-temperature conditions, typical for first turbine stage in a flow of controlled-intensity, artificiallygenerated turbulence. The vane cooling was internal, accomplished by 10 channels in each vane with cooling-air flow. Numerical simulations of the experiment were conducted applying two turbulence models of the k-omega family: k-omega-SST and Transition SST implemented in the ANSYS Fluent solver. Boundary conditions for the simulations were set based on conditions of experiment: total pressures and total temperature on inlet to cascade, static pressure on the outlet of the cascade and heat flux on the surface of cooling channels. The values of heat flux on the surface of cooling channels were evaluated based on Nusselt numbers obtained from experiment and varied in time until steadystate conditions were obtained. Two test cases, one with subcritical outlet flow, and another one, with supercritical outlet flow were simulated. The result of experiment-distributions of pressure, surface temperature, and heat transfer coefficients on the vane external surface were compared to results of numerical simulations. Sensitivity of the vane surface temperatures and heat transfer coefficients to turbulence models and to boundary-condition values of parameters of turbulence models: turbulence energy and specific dissipation of turbulence energy was also studied.
\end{abstract}

Keywords: aircraft engines, mechanical engineering, engine parts, simulation and modelling

\section{Introduction}

First-stage vane rows of a gas turbine are working in a high-pressure, high-temperature environment, which often require vane cooling by air bled from last compressor stage. Vane cooling may involve coolant flow emanating from orifices on vane surface, or in internal-cooling solutions, may be internal, with coolant-flow inside cooling channels. For internally cooled vanes, results of computational simulations of heat exchange on the surface of vanes depend on details of computational models, including chosen turbulence model and modelling of laminar-turbulent transition. In the present work results of simulations of a heat-exchange experiment are shown, involving comparison of results obtained with two models of turbulence in a conjugate flowand-heat exchange solver to experimental results. Similar problems regarding modelling of turbulence and laminar-turbulent transition, although with reverse direction of heat flux, occur in other problems in aeronautics, e.g. in simulations of operation of anti-icing devices.

\section{Details of experiment in vane cooling}

In the experiment, a cascade composed of three vanes with internal cooling channels was set in a hot-gas flow originated from pressurized burning chamber. Between the burner exit and vane cascade a set of rods was located, producing turbulence in the hot gas. The gas flow was a result of pressure difference between the burner exit and pressure in the exit plane behind the cascade Geometric details of the experimental setup and measurement equipment are described in [1] and shown in Fig. 1. Results of experiment, obtained by authors of Ref. [1], included distributions of 
temperature and pressure on vane surface, as well as distributions of heat transfer coefficient evaluated, based on vane surface temperature and hot-gas total temperature. Flow velocity was regulated by valves at the exit of the cascade, changing exit pressure, exit Mach number, and Reynolds number of the flow around the cascade. Inlet total temperature and pressure, inlet and exit static pressure, Mach number were measured for each run in the experiment. Vane surface was instrumented with static pressure taps and temperature sensors for recording surface distributions of static pressure and temperature. In addition, for each cooling channel, inlet and outlet temperature, static pressure and mass flow was measured.

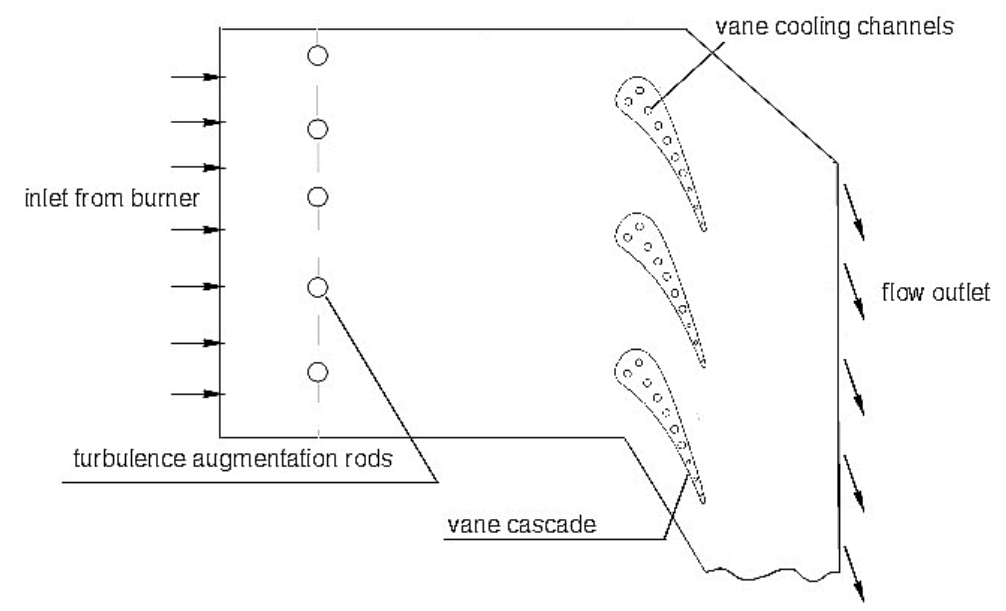

Fig. 1. General scheme of the experimental setup in work [1]

\section{Details of the flow and heat exchange simulation model}

In the present work, the computational domain included solid and fluid zones. Numerical simulations of flow and heat transfer on vane cascade were conducted with ANSYS Fluent solver. In the fluid zone, unsteady Navier-Stokes equations were solved and the flow simulations included application of two turbulence models: k- $\omega$-SST and Transition SST. In the solid zone, heat conduction equations were solved. The fluid zone was a fragment of the cross-sectional area of the test space surrounding the central vane of the cascade constrained by surfaces with imposed boundary conditions of periodicity above and below the vane, pressure inlet in front of the cascade fragment, and pressure exit behind the cascade fragment. The solid zone comprised cross-section of the central vane of the cascade, made of ASTM type 310 stainless steel, and included the cooling holes, where boundary conditions of heat flux were imposed. The heat transfer coefficient for each of the cooling channels was evaluated based on the formula for Nusselt numbers used in [1], given here as Eq. (1) hole diameter and vane material thermal conductivity:

$$
N u_{D}=\operatorname{Cr}\left(0.022 \operatorname{Pr}^{0.5} \operatorname{Re}_{D}^{0.8}\right),
$$

where $N u_{D}$ is Nusselt number for the cooling channel of diameter $D, P r$ is Prandtl number for coolant flow, $\operatorname{Re}_{D}$ is Reynolds number based on channel diameter and $\mathrm{Cr}$ is a correcting factor, depending on Prandtl and Reynolds numbers, accounting for thermal entrance effects. Values of $\mathrm{Cr}$ are provided in [1] for each test. Based on equation (1) heat transfer coefficient and heat flux for each cooling channel was evaluated and applied as boundary condition for internal cooling. Heat flux varied in time, as it depended on coolant temperature, provided in [1] for each hole, and average temperature of each hole wall, evaluated in each time step. View of computational domain, including contour of temperature in fluid and solid domain is shown in Fig. 2. For the external flow, the pressure inlet boundary conditions: total pressure and total temperature were applied as provided in work [1] for each of the test run. Static temperature on the pressure outlet surface was evaluated based on total temperature and exit Mach number given in [1]. 

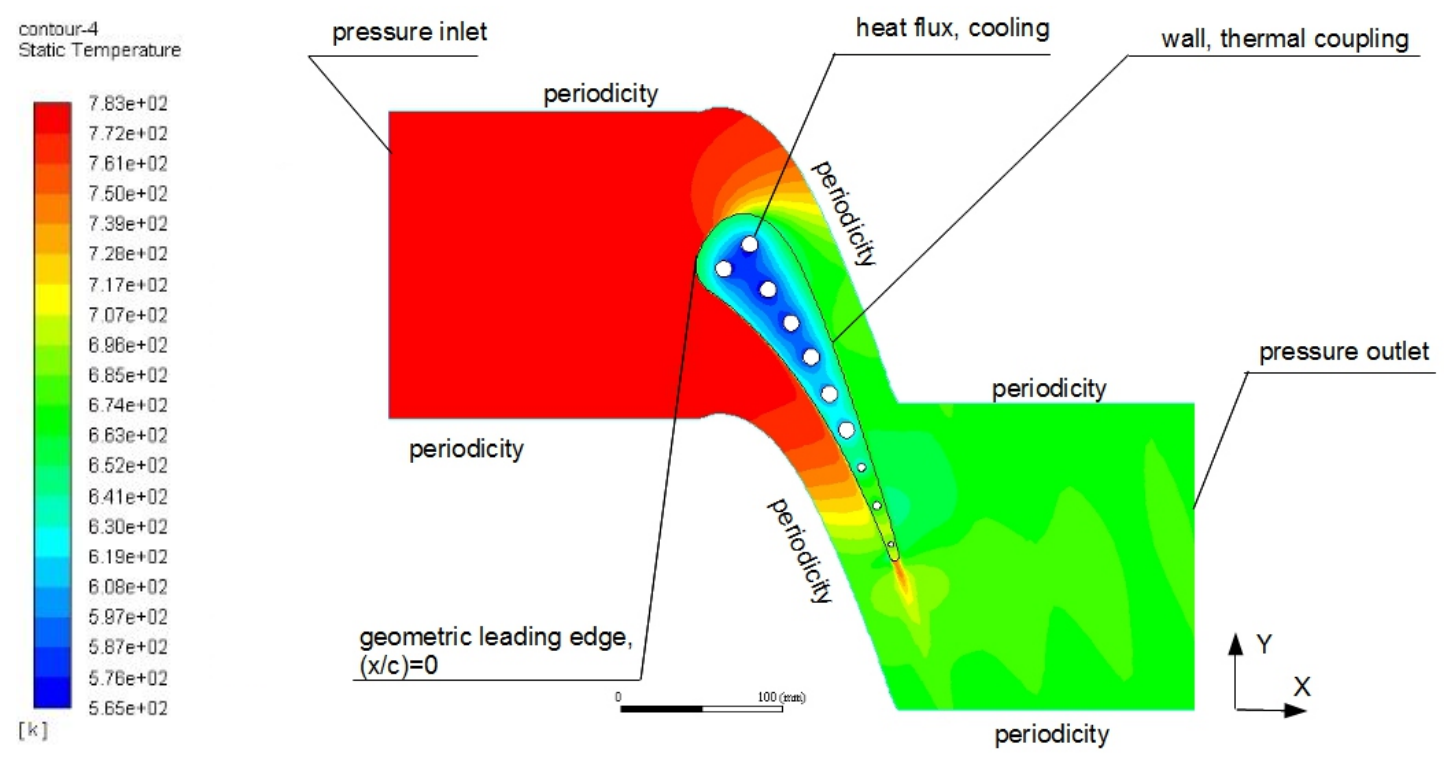

Fig. 2. Contours of temperature in the computational domain (fluid and solid zones) and applied boundary conditions

In the first step, the exit pressure was evaluated from the isentropic formula, assuming exit total pressure $p_{t}$ equal to inlet total pressure:

$$
\frac{p_{t}}{p}=\left(1+\frac{\gamma-1}{2} M^{2}\right)^{\gamma /(\gamma-1)}
$$

where $\gamma$ is ratio of constant heats, $\gamma=c_{p} / c_{v}, M$ is exit Mach number given in [1]. In addition, exit isentropic velocity was evaluated for the assumed exit Mach number using equation:

$$
V_{i s}=M \cdot \sqrt{\gamma R T}
$$

where $R$ is gas constant and $T$ is exit static temperature. In real, viscous flow, there occurs loss of total pressure causing decrease of exit velocity and Mach number. The velocity loss coefficient $\psi$ was evaluated as:

$$
\psi=V_{\text {visc }} / V_{\text {is }}
$$

where $V_{\text {visc }}$ is exit velocity obtained as result of solution of viscous flow, as surface-averaged integral over the surface of the pressure outlet. In the same manner, the viscous-flow exit total pressure $p_{t}$ visc was obtained. In the second step the corrected exit static pressure was obtained from formula (2) applying the value of total pressure $p_{t}=p_{t}$ visc. The coefficient $\psi$ may serve as indication of the accuracy of computation of viscous losses, as it may be compared with literature data, or evaluated using engineering methods, e.g. [2, 3]. Setting inlet boundary values of turbulence variables was done using the option of explicit setting of turbulence kinetic energy $k$ and specific dissipation $\omega$ on inlet surface. Turbulence intensity is related to turbulence kinetic energy by formula:

$$
T u=\frac{\sqrt{\left(\frac{2}{3}\right) k}}{V_{a v}},
$$

where $T u$ is turbulence intensity (non-dimensional), $k$ is turbulence kinetic energy $\left[\mathrm{m}^{2} / \mathrm{s}^{2}\right]$, and $v_{a v}$ is average velocity in the channel $[\mathrm{m} / \mathrm{s}]$. Specific dissipation, $\omega[1 / \mathrm{s}]$, is related to turbulence kinetic energy by the formula:

$$
\omega=\frac{k^{1 / 2}}{C_{\mu} \cdot l}=\frac{k^{1 / 2} \cdot C_{\mu}^{-1 / 4}}{0.07 \cdot L}
$$

where $l$ is turbulence length scale [m] and is related to characteristic dimension $L$ of the channel. 
$\mathrm{C}_{\mu}$ equal to 0.09 , is a non-dimensional constant. Guidance on setting the value of $L$ is provided in ANSYS Fluent user guide [4]. For fully developed internal flows, $L$ may be specified equal to the hydraulic diameter of the channel. In flows with artificially-produced turbulence $L$ is equal to characteristic length of the turbulators.

\section{Effects of turbulence modelling on results on vane surface temperature and heat transfer}

Two turbulence models were applied in the simulations of flow in the cascade: k- $\omega$-SST and transition SST. The model k- $\omega$-SST was applied with the option "Intermittency transition" alternatively switched off and on, in order to compare the effects of laminar-turbulent transition on surface temperature and heat exchange with results of the Transition SST model and with results of the experiment. This way, three sets of results of flow and heat transfer simulations are compared with results of experiment, including the "basic" model k- $\omega$-SST assuming fully turbulent flow. In all cases the "viscous heating" option was switched on. The simulations were conducted for two test conditions, designated in work [1] as "Run 107" and "Run 112". In the run 107, the flow exiting from test space was supersonic, and in the run 112, it was subsonic. The experimental boundary conditions for both test runs are shown in Tab. 1.

Tab. 1. Inlet and outlet boundary conditions for simulated test runs

\begin{tabular}{|l|c|c|}
\hline \multicolumn{1}{|c|}{ parameter } & Run 107 & Run 112 \\
\hline inlet total pressure [Pa] & 311919 & 321709 \\
\hline inlet total temperature [K] & 798 & 783 \\
\hline inlet turbulence intensity Tu [\%] & 6.5 & 8.3 \\
\hline exit Mach number [-] & 1.05 & 0.9 \\
\hline
\end{tabular}

The simulation procedure involved proceeding from initial conditions of uniform flow parameters and temperature in the fluid and solid zone, to equilibrium state, characterized by constant-in time distributions of flow parameters and gradients in temperature. For practical reasons it was assumed that the steady state was reached, when rate of change of medium vane surface temperature was below $0.1 \mathrm{~K} / \mathrm{min}$. The computational time to reach steady-state conditions from uniform-temperature initial conditions was approximately $300 \mathrm{~s}$. It cannot be compared, however, to the experiment, due to lack of this information in work [1]. The numerical solutions were obtained for grid composed of quadrilateral elements and the $\mathrm{y}^{+}$parameter was well below unity, equal to, approximately 0.4 over the entire vane surface.

Figure 3 shows distributions of static-to-total pressure ratio for three numerical solutions for each test run. It can be seen, that for both test runs the numerical solutions are identical. For the run 107 with supersonic exit flow a shockwave is clearly visible at approximately $x / c=0.7$, which is not visible in the experimental results, most likely due to scarcity of the pressure sensors. In case 112 with lower Mach numbers shockwave does not appear. The following Figures, from Fig. 4 to Fig. 9 present distributions of vane surface temperature and heat transfer coefficient for the run 107 (Figs. 4 to 6) and for run 112 (Figs. 7 to 9). The heat transfer coefficient $h(x)\left[\mathrm{W} / \mathrm{m}^{2} \mathrm{~K}\right]$ in the present work and in work [1] was determined using equation:

$$
h(x)=\frac{d T}{d n}(x) \cdot k_{c} \cdot \frac{1}{\left(T_{t}-T(x)\right)},
$$

where $k_{c}$ is heat conduction coefficient $[\mathrm{W} / \mathrm{mK}], T_{t}$ is total fluid temperature and $T(x)$ is local surface vane temperature, $\frac{d T}{d n}(x)$ is vane temperature gradient $[\mathrm{K} / \mathrm{m}]$ in direction normal to vane surface computed on the surface. It must be noted here, that values of heat transfer coefficient denoted in Fig. 4-9 as experimental values depend on measured temperature and computed 

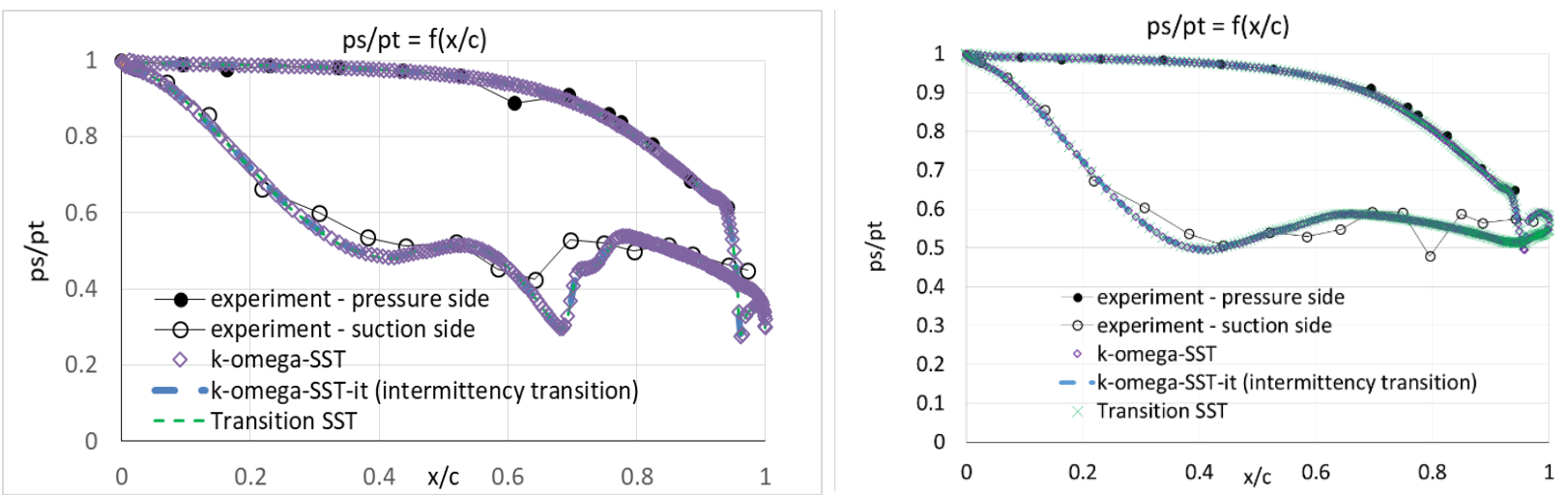

Fig. 3. Distributions of static-to-total pressure ratio for runs 107 (left) and 112 (right) for three computational models compared with results of experiment
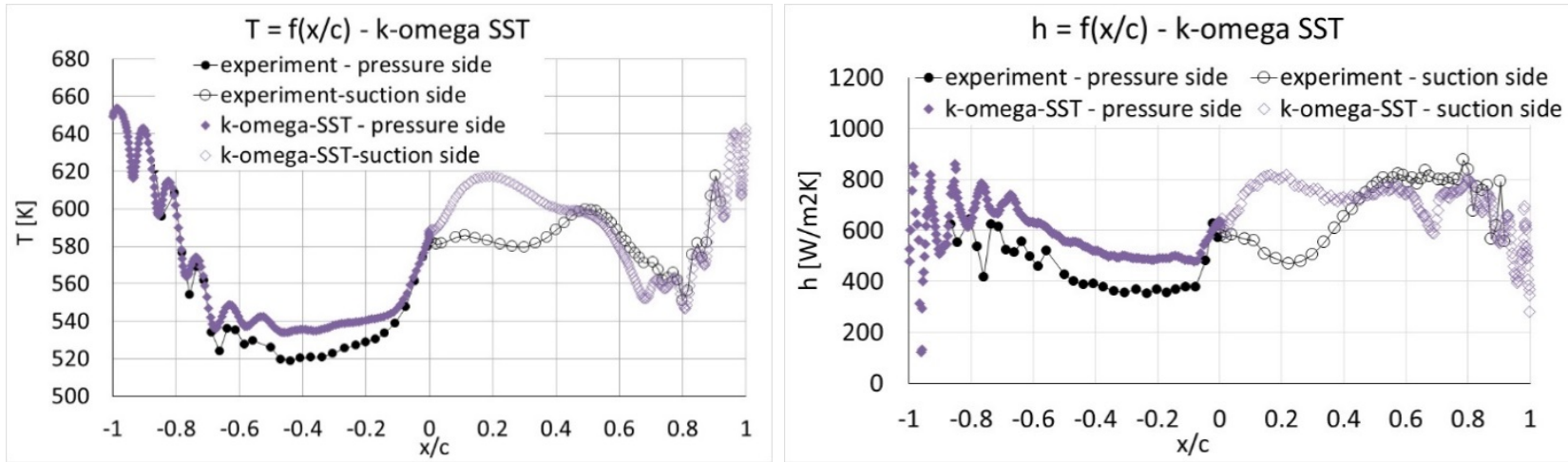

Fig. 4. Distributions of surface temperature and heat transfer coefficient computed with k-omega-SST turbulence model, compared with results of experiment, run 107
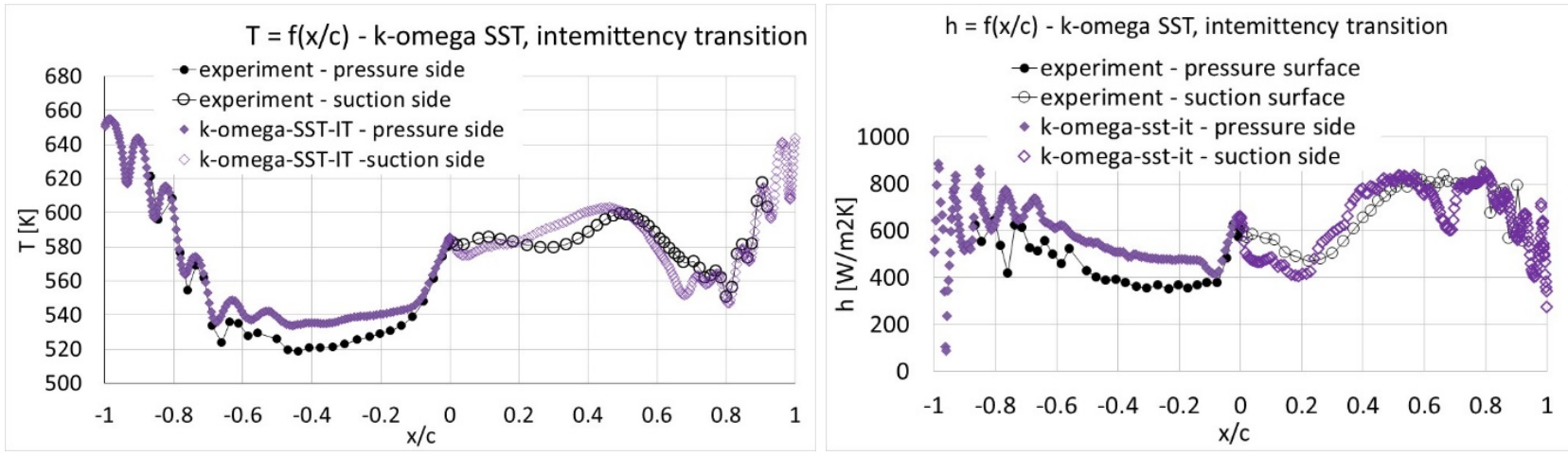

Fig. 5. Distributions of surface temperature and heat transfer coefficient computed with k-omega-SST turbulence model with option ,, intermittency transition”, compared with results of experiment, run 107
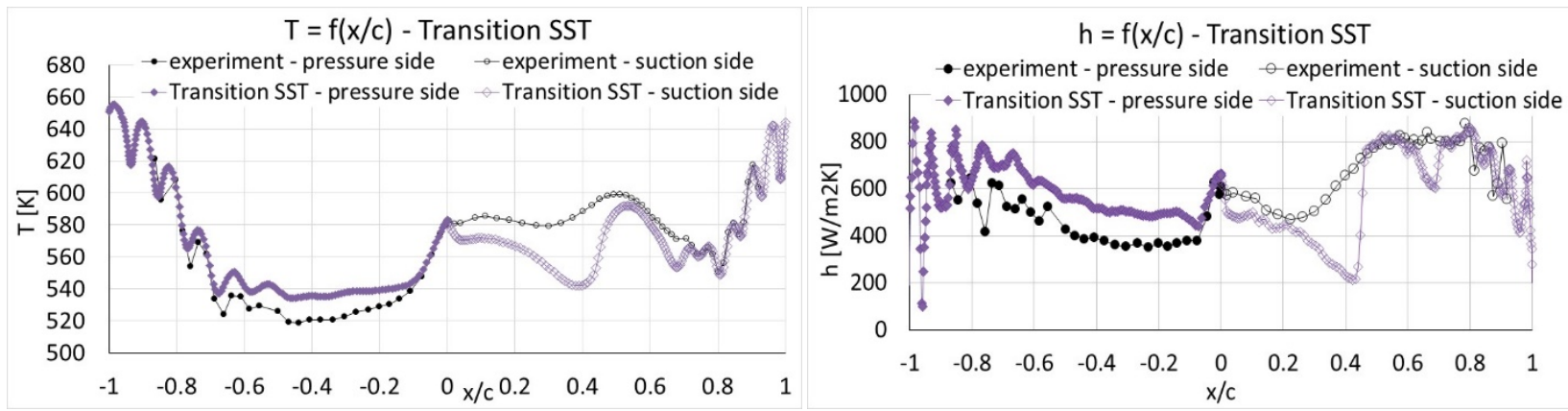

Fig. 6. Distributions of surface temperature and heat transfer coefficient computed with Transition SST turbulence model, compared with results of experiment, run 107 

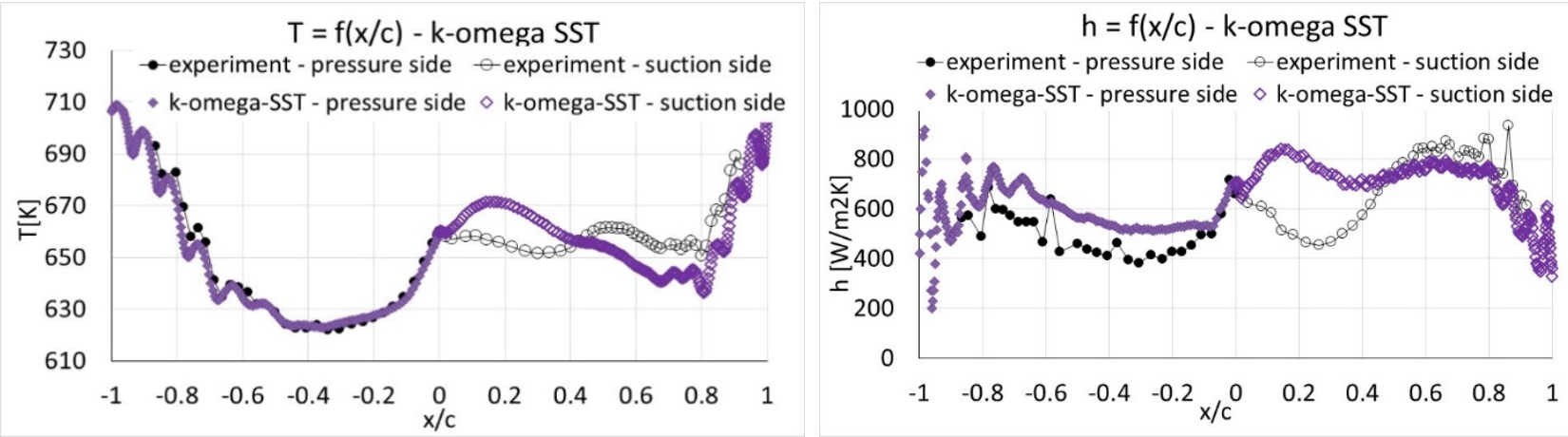

Fig. 7. Distributions of surface temperature and heat transfer coefficient computed with k-omega-SST turbulence model, compared with results of experiment, run 112
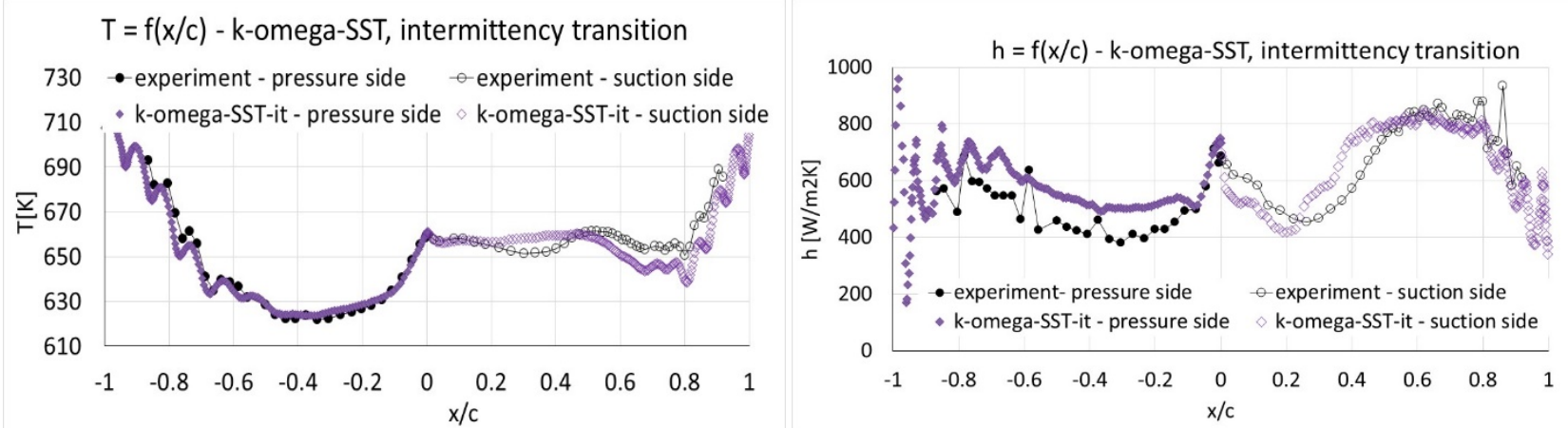

Fig. 8. Distributions of surface temperature and heat transfer coefficient computed with k-omega-SST turbulence model with option ,, intermittency transition", compared with results of experiment, run 112
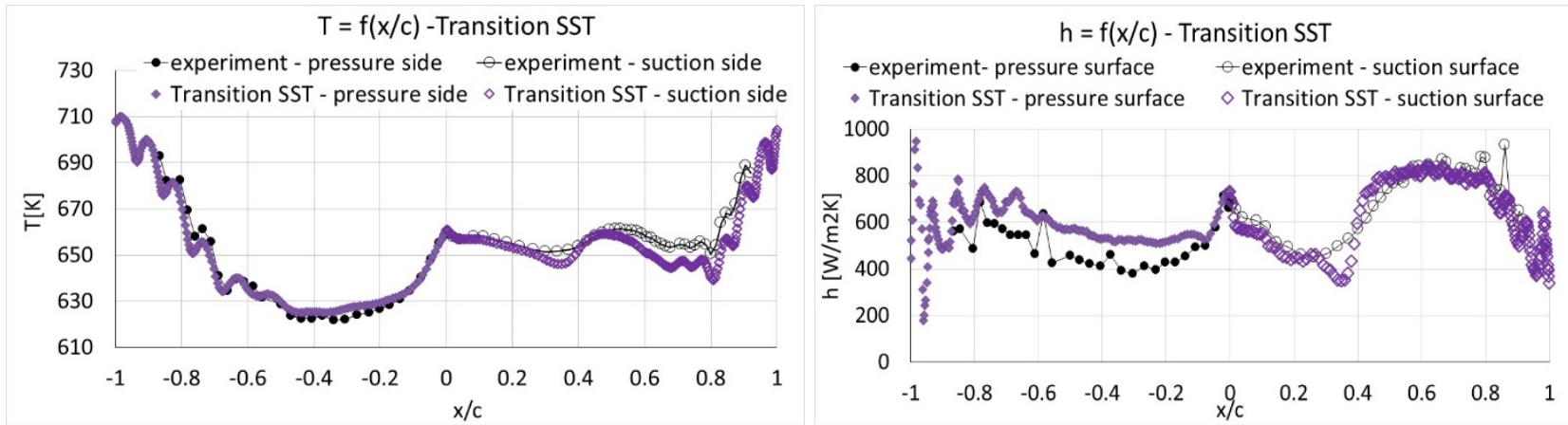

Fig. 9. Distributions of surface temperature and heat transfer coefficient computed with Transition SST turbulence model, compared with results of experiment, run 112

derivative of temperature, which was conducted in [1] using a finite-element method. For clarity the pressure side in Figs. 4-9 was shown on the left side of the graphs, with negative values of $x / c$ ( $c$ is vane axial chord), and $x / c=0$ is a point on geometric leading edge, as shown in Fig. 2.

For both test runs, the relative error of computed temperature distributions is lower than relative error of heat transfer coefficients. It can be explained by dependence of heat transfer coefficient computed by Eq. (7), on vane surface temperature having its error margin by and possible differences in temperature gradient computed by the present method and the method applied in work [1]. It can also be seen that surface temperatures computed by the present method for subsonic run 112 are closer to experimental values than temperatures computed for run 107 (supersonic exit and shockwaves on suction surface). Both turbulence models: k-omega-SST with option "Intermittency Transition" and the Transition SST model predicted different range of transitional flow in the frontal region of the vanes. Fig. 10 presents changes of intermittency (probability of boundary layer being turbulent) computed with both models for the run 112 on an 
auxiliary surface in the boundary layer, $h=0.05 \mathrm{~mm}$ above vane surface. The Transition SST predicts a narrower transitional-flow, low-intermittency area. The likely reason for this is differences in the design of these models. The Transition SST solves two transport equations for determination of the transition: one for transition momentum-thickness Reynolds number $R \widetilde{e_{\theta t}}$, and second one for intermittency [4]. The second model, k-omega-SST with intermittency transition option on does not solve the transport equation for $R \widetilde{e_{\theta t}}$ and has different source terms in the transport equation for intermittency.

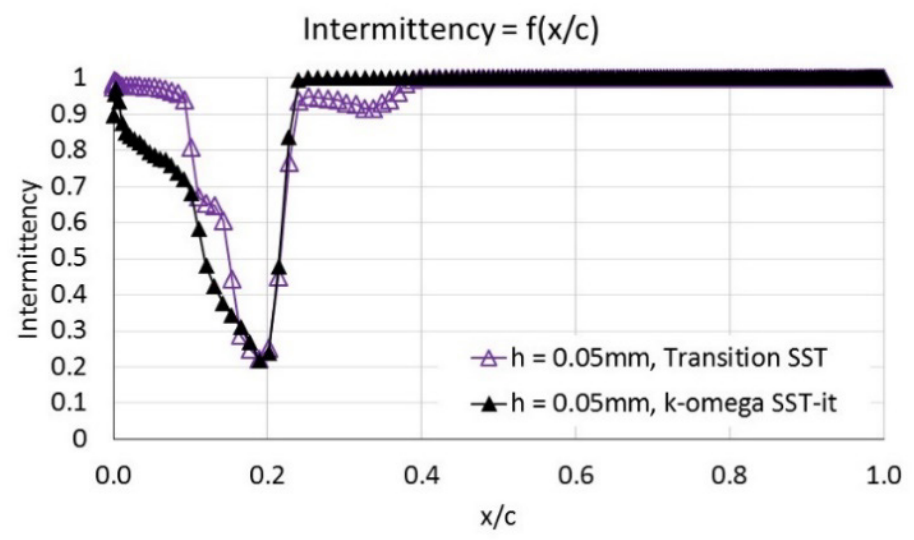

Fig. 10. Changes of intermittency along an auxiliary surface, $h=0.05 \mathrm{~mm}$ above suction vane side, run 112

Sensitivity of the solution to changes in boundary conditions of turbulence variables was also studied. Choosing in Eq. (6), the characteristic length L is equal to height of the channel in front of the vane cascade results in the value of specific dissipation, $\omega$ equal approximately $5001 / \mathrm{s}$. However, for such a high value of $\omega$, the dissipation of turbulence in the mesh region between inlet surface and vane leads to decrease of turbulence intensity reaching the vane. In order to minimize this phenomenon, a lower value of $\omega, \omega=1001 / \mathrm{s}$ was applied on the pressure inlet surface for both runs.

Effects of choosing of either value for $\omega$ at the inlet surface on turbulence kinetic energy reaching the vane cascade and on vane, surface temperature is shown in Fig. 11 for run 107. The changes in surface temperature are restricted to a narrow region on the suction surface and are negligible. Effects of possible error in applied boundary-condition value of turbulence kinetic energy $k$ on vane surface temperature were evaluated using run 112 as an example, by decreasing $k$ to value of 75.6 , equivalent to $10 \%$ decrease of turbulence intensity. The results are shown in Fig. 12. It can be seen, that decrease of the inlet turbulence kinetic energy, equivalent to $10 \%$ decrease of turbulence intensity leads to very slight decrease of surface temperature, constrained to approximately one-third of the suction side.
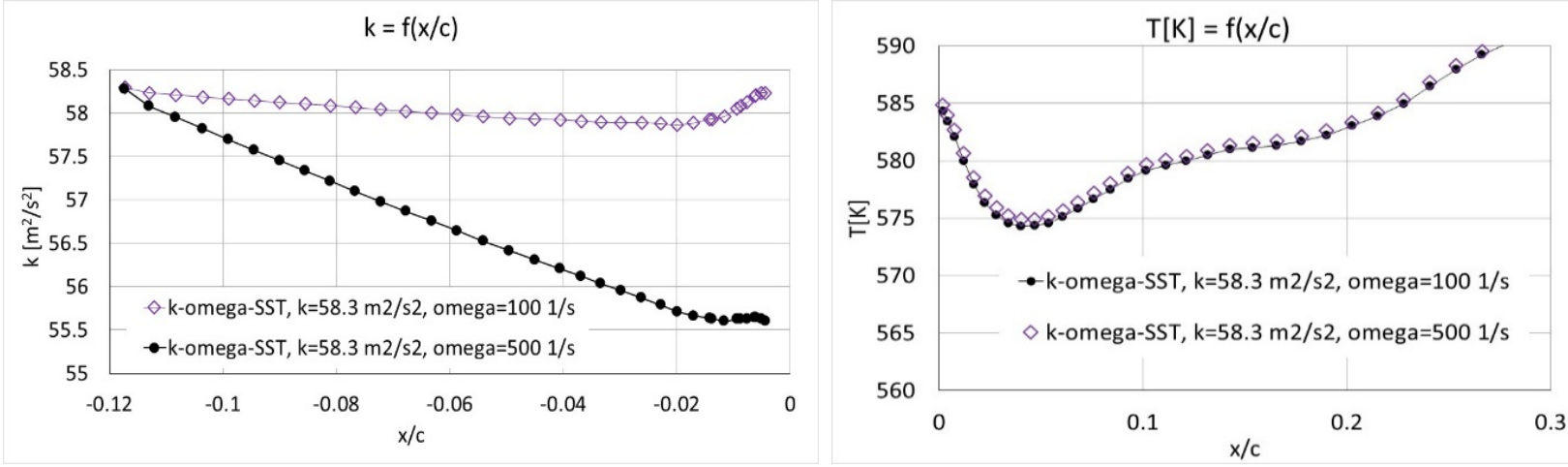

Fig. 11. Effects of change in inlet value of specific dissipation rate $\omega$ on turbulence kinetic energy reaching vane cascade and vane surface temperature 

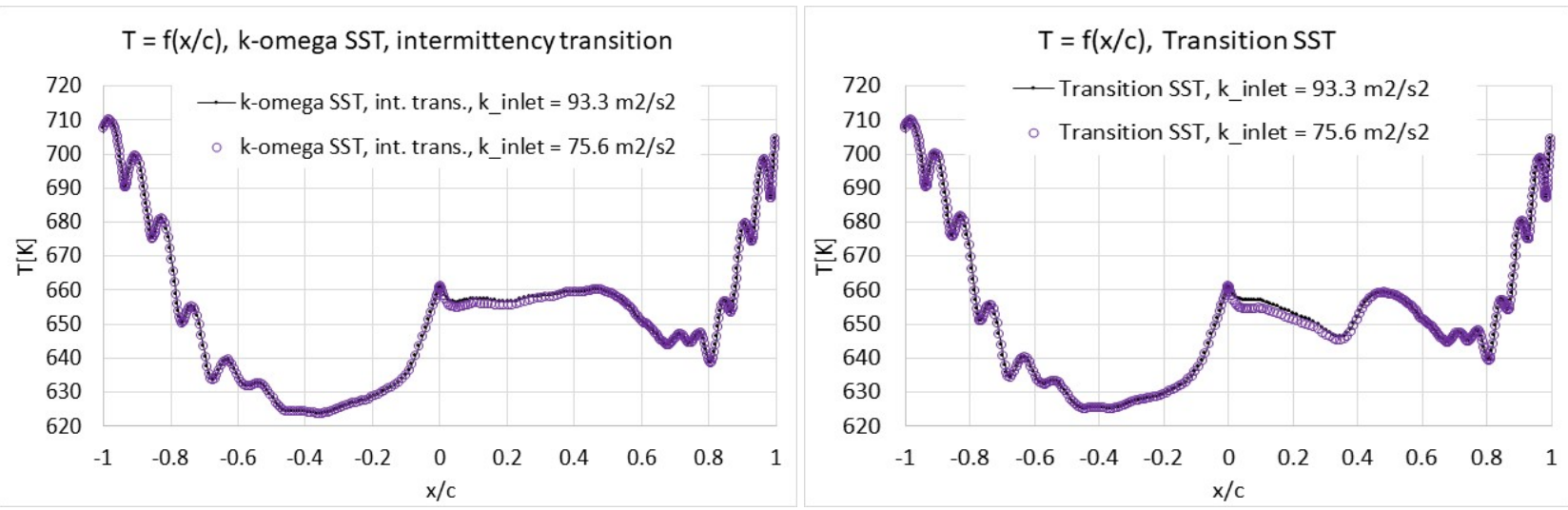

Fig. 12. Comparison of distributions of vane surface temperature computed for nominal value of turbulence kinetic energy and value corresponding to $10 \%$ decrease of inlet turbulence intensity.

\section{Conclusions}

The results of simulations of high-temperature gas flow over the vane cascade indicate that modelling of laminar-turbulent transition and transitional flow is necessary for correct determination of surface temperatures over vane suction surface. The agreement between computed and measured vane surface temperatures was better for the subsonic-exit case 112 than for the case 107 with significant areas of supersonic flow. In case 107, for the three tested turbulence models there appeared similar differences between computed and measured temperatures on the vane pressure side. The differences on the suction side were more model-specific. Also in case 112, where agreement with experimental results was much better for the tested models of turbulence, model-specific differences occurred on the vane suction side. While it is difficult to trace down the cause of the temperature differences on pressure side in case 107, it can be stated, that the model k-omega-SST-intermittency-transition was in reasonably good agreement with experimental results on the suction side of the vane in the subsonic case 112 and supersonic case 107. In both cases, it avoided producing results contrasting with the experiment. As far as the heat transfer coefficient is concerned, it is the opinion of the author of this paper, that high differences between the experimental and computational results have two sources. One of them is difference between vane surface temperatures, visible in Fig. 4-9, on both vane sides, and the other possible cause is difference in temperature gradient $d T / d n$ within the vane, between the results of the present work and the work [1]. However, it is difficult to verify, as values of temperature gradient are not provided with the results [1]. The final conclusion with regard to modelling turbulence in flows with heat exchange is that the model k-omega-SST-intermittency-transition is the safest option within the tested models to choose in subsonic and supersonic flow regime.

\section{References}

[1] Hylton, L., Mihelc, M. S., Turner, E. R., Nealy, D. A., York, R. E., Analytical and Experimental Evaluation of the Heat Transfer Distribution over the Surfaces of Turbine Vanes, Detroit Diesel Allison, Division of General Motors Corporation, Contract NAS 3-22761, May 1983.

[2] Craig, H. R, Cox, H. J. A., Performance Estimation of Axial Flow Turbines, Proc. Instn. Mech. Engrs., Vol. 185, 32/71, pp. 407-424, 1970-71.

[3] Back da Trinidade, D., Bugała, P., Simone, D., Review of Loss Models for High Pressure Turbines, Journal of KONES Powertrain and Transport, Vol. 25, No. 2, pp. 38-44 2018.

[4] ANSYS Documentation, available at https://ansyshelp.ansys.com. Manuscript received $21 \overline{\text { March 2019; approved for printing } 25}$ June 2019 